\title{
Penjemur Kerupuk Otomatis Menggunakan Sistem Kecerdasan Buatan Arduino Uno Dengan Menerapkan Metode Fuzzy Logic Controller (FLC)
}

\author{
Risal Suandi \\ Program Studi Teknik Informatika, STMIK Budi Darma, Medan, Indonesia \\ Email: risalsuandi23@gmail.com \\ Submitted 31-03-2020; Accepted 20-02-2020; Published 26-04-2020
}

\begin{abstract}
Abstrak
Pabrik kerupuk jangek denai adalah perusahaan yang terletak di jalan denai Kota medan, pabrik ini sehari-hari memperoduksi kerupuk jangek, pada tahap produksi ada sebuah tahapan penjemuran kerupuk jangek yang digunaka secara manual, dimana kerupuk diletakan di luar ruangan yang terkena panas matahari pada tahap penjemuran. Pada saat musim penghujan tiba hal ini membuat banyak waktu tersita pada saat proses penjemuran karna sering tiba-tiba hujan turun, maka kerupuk harus segera dimasukan ke dalam atau diletakan di tempat yang kering tidak terkena air hujan . Metode FLC adalah sebuah metode yang sering digunakan pada pembuatan sistem kecerdasan buatan yang di terapkan pada sebuah mikrokontroler Arduino uno dimana metode tersebut hanya mengenal on atau Off , 0 atau 1, tidak ada yang samar. Dari gambaran permasalahan di atas maka penulis membuat suatu sistem kecerdasan buatan yang diterapkan pada sebuat alat yaitu arduino uno, dimana sistem tersebut berpikir seperti manusia, yang dapat berpikir seperti saat hujan sehingga alat tersebut akan memindahkan atau menutup kerupuk yang sedang dijemur agar tidak terkena hujan dengan menggunakan sebuah metode FLC yang diterapkan pada arduino uno.
\end{abstract}

Kata Kunci: Penjemur kerupuk, Arduino Uno, Metode FLC .

\begin{abstract}
Denang jangek cracker factory is a company located on the road denai Kota medan, this factory everyday produces jangek crackers, at the stage of production there is a stage of drying jangek crackers used manually, where crackers are placed outside the room exposed to the sun's heat at the drying stage. When the rainy season arrives this makes a lot of time taken up during the drying process because often it rains suddenly, then the crackers must be immediately put in or placed in a dry place not exposed to rain water. The FLC method is a method that is often used in making artificial intelligence systems that are applied to an Arduino uno microcontroller where the method only recognizes on or Off, 0 or 1 , nothing is vague. From the description of the problem above, the writer makes an artificial intelligence system that is applied to a device, namely Arduino Uno, where the system thinks like humans, who can think like when it rains so that the tool will move or close crackers that are being dried in the sun so that it is not exposed to rain with using an FLC method applied to Arduino Uno.
\end{abstract}

Keywords: Crackers drying, Arduino Uno, FLC Method.

\section{PENDAHULUAN}

Kota Medan adalah wilayah yang berada pada Negara Indonesia yang memiliki dua musim yaitu musim hujan dan musim panas. Pabrik kerupuk jangek denai adalah sebuah perusahaan yang terletak di jalan denai Kota Medan, pabrik ini sehar-hari memperoduksi kerupuk jangek, pada tahap produksi ada sebuah tahapan pengeringan kerupuk jangek dengan dilakukan penjemuran yang digunakan secara manual, dimana kerupuk diletakan di luar ruangan yang terkena panas matahari. Pada saat musim penghujan tiba hal ini membuat banyak waktu tersita pada saat proses penjemuran karena sering tiba-tiba hujan turun, maka kerupuk harus segera dimasukan ke dalam atau diletakan di tempat yang kering tidak terkena air hujan. Hal inilah yang memakan banyak waktu dalam proses pembuatan kerupuk jangek karena keseringan memindah-mindahkan kerupuk keluar dan kedalam agar tidak terkena air hujan saat musim penghujan tiba.

Metode Fuzzy Logic ini diformulasikan dalam rangka mencari nilai tengah antara bilangan Aristoteles 0 dan 1. Logika biner 0 atau 1 dasarnya berfikirnya adalah dari filsuf Aristoteles yang mengajarkan hukum berfiki bahwa sesuatunya mesti tergolong benar atau salah. Logika biner hanya mengenal on atau off, hidup atau mati, gelap atau terang, benar atau salah. Tidak ada yang samar-samar, tidak ada abu-abu yang ada hanya hitam atau putih. Jika tidak 1 maka 0 , jika tidak gelap berarti terang dan ini adalah sesuatu yang logis. Dan ini juga yang menjadi dasar perkembangan teknologi digital saat ini hal itu seiring dengan usaha untuk membuat komputer yang bekerja seperti cara manusia berfikir. Sebab komputer pada dasarnya adalah sebuah mesin hitung yang tidak berfikir. Sebelumnya Plato sudah mencetuskan ide adanya daerah ketiga diantara benar dan salah. Ini yang menjadi dasar logika fuzzy yang memformulasikan bilangan antara 0 dan 1 . Dapat disimpulkan logika fuzzy adalah suatu cara yang tepat untuk memetakan suatu ruang input kedalam suatu ruang output.

Pabrik kerupuk denai merupakan perusahaan skala menengah yang Sehari-hari perusahaan ini memproduksi kerupuk jangek dari bahan dasar kulit sapi atau kerbau, hingga menjadi sebuah kerupuk siap hidang untuk dimakan ,pada saat musim penghujan tiba hal ini yang membuat banyak waktu tersita karena sering memindah-mindahkan kerupuk jangek agar tidak terkena air hujan ,untuk itu sangat penting membuat sebuah alat penjemur kerupuk otomatis untuk membantu penjemuran yang manual dirubah menjadi otomatis yang di perlukan menjadi lebih cepat dan efesien.

Penelitian yang telah dilakukan menggunakan metode FLC yaitu penelitian yang dilakukan oleh (Yulianti Paula Bria. semnasIf 2012, 30 Juni 2012) yang mengangkat judul Pengembangan Aplikasi FLC (Fuzzy Logic Controller) Untuk Pengereman Kereta Api Di Stasiun Dan Simulasinya, dimana metode FLC ini dibuat untuk mengatur kecepatan kereta saat kereta melakukan pengereman [1]. 
Selanjutnya metode FLC dilakukan penelitian oleh ( Pilipus Tarigan, Sinar Sinurat, Marzuki Sinambela. IEEE 25 Januari 2016) yang melakukan penelitian berjudul Implementation of a Mamdani fuzzy logic controller for building automation using electronic control based on AT89S51, dimana metode Fuzzy Logic Controller ini digunakan untuk pengaturan lampu secara otomatis yang tersistem dengan komputerisasi yang diterapkan kepada Mikrokontroler AT89S51 yang mengatasi masalah menghidupkan dan mematikan lampu secara manual yang membuang banyak waktu, tenaga fisik dan biaya [2].

Penjemur kerupuk ini akan dirancang menggunakan sebuah kendali cerdas Arduino yang di program menggunakan metode FLC yang bersifat logis, dimana penjemur ini akan secara otomatis berpikir seperti manusia dimana ketika hujan tiba posisi penjemur akan memasukan kerupuk jangek ke dalam ruangan yang tidak terkena air hujan, pada saat perancangan penjemur kerupuk jangek ini dibuat sebuah prototype berupa sebuah alat yang menunjang system penjemur seperti mikrokontroler Arduino uno sebagai pengendali cerdas dari semua alat yang digunakan dan beberapa sensor, seperti sensor cahaya dan sensor air yang menjadi input atau masukan terhadap kendali cerdas Arduino uno, roda penarik dan batrai sebagai penarik kerupuk jangek keluar masuk penjemur.

\section{METODE PENELITIAN}

\subsection{Kecerdasan Buatan}

Dalam kehidupan manusia dewasa ini, hampir semua aspek kehidupannya tidak terlepas dari peran sistem kendali. Mulai dari peralatan-peralatan dirumah seperti AC, kulkas, televisi, pemanas air, oven, dan masih banyak lagi, peralatan yang di dalam kendaraan sepeda motor, mobil, kereta api, kapal laut, pesawat terbang dan pesawat ruang angkasa, maupun peralatan di kantor maupun di tempat umum seperti lift, lampu lalu lintas, dan peralatan instrumentasi lainnya. Semua peralatan yang memiliki sistem kendali didalamnya dimaksudkan untuk memudahkan pekerjaan manusia, memberikan kenyamanan, keselamatan dan hasil kerja yang baik.

\subsection{Mikrokontroler Arduino}

Arduino adalah kit elektronik atau papan rangkaian elektronik open source yang didalamnya terdapat komponen utama, yaitu sebuah chip mikrokontroler dengan jenis $A V R$ dari perusahaan Atmel. Mikrokontroler itu sendiri terdiri dari atau IC (integrated circuit) yang bisa di program menggunakan komputer. Tujuan menanamkan program pada mikrokontroler adalah agar rangkaian elektonik dapat membaca input, memproses input tersebut kemudian menghasilkan output sesuai yang diinginkan. Jadi mikrokontroler bertugas sebagai 'otak' yang mengendalikan input, proses dan output sebuah rangkaian elektronik

\subsection{Fuzzy Logic Controler (FLC)}

Sistem kendali fuzzy berkembang dengan pesat terutama di Jepang. Banyak barang konsumen yang telah diproduksi, yang didalamnya terdapat sistem fuzzy sebagai pengendalinya, konsumsi, sistem kendali fuzzy juga diaplikasikan kedalam sistem seperti elevator, kereta api, crane, otomotif (mesin,transmisi otomatis,sistem pengereman), dan sistem kendali lalu lintas, dan juga diaplikasikan dalam bentuk perangkat lunak atau program komputer seperti diagnosis medis, keamanan, dan kompresi data.

Sistem kendali fuzzy yang merupakan aplikasi teori fuzzy dibidang kendali, pertama kali dikembangkan oleh Ebrahim Mamdani tahun 1947 yang merancang sistem kontrol pada mesin uap. Sistem fuzzy berkerja dengan himpunan fuzzy dan operasi himpunan fuzzy. Himpunan fuzzy merepresentasikan nilai linguistik suatu variabel, misalnya variabel suhu dinyatakan dengan nilai linguistik panas, sejuk dan dingin, variabel jarak dinyatakan dengan jauh, sedang, atau dekat. Sistem fuzzy akan melakukan inferensi atau penarikan kesimpulan berdasarkan nilai linguistik variabel input dan akan menghasilkan keputusan yang berupa nilai linguistik variabel output. Dalam proses inferensi itulah terjadi operasi himpunan-himpunan fuzzy seperti operasi $A N D, O R$, dan implikasi. Keputusan sistem fuzzy ditentukan berdasarkan aturan-aturan yang disebut basis aturan fuzzy yang berisi pernyataan-pernyataan relasi variabel - variabel input ke variabel output. diagram sistem fuzzy tipe Mamdani, bagian fuzzifier digunakan untuk melakukan fuzzifikasi yaitu mengubah nilai numerik variabel input (umumnya berupa nilai hasil pembacaan sensor) ke nilai linguistic yang berupa derajat keanggotaan pada suatu himpunan fuzzy variabel input. Sedangkan bagian defuzzifier akan melakukan proses yang sebaliknya yaitu mengubah nilai linguistik hasil inferensi fuzzy kenilai numerik yang siap dikirimkan ke output.basis aturan fuzzy berisi aturan IF-THEN yang menggambarkan pemetaan hubungan nilai-nilai variabel input dan variabel output

\section{HASIL DAN PEMBAHASAN}

Kebutuhan akan efektivitas dan efisiensi sangat diutamakan dalam berbagai bidang terutama bidang industri. Hal tersebut mendorong manusia untuk berkreasi dan berinovasi dalam bidang teknologi untuk menciptakan sebuah alat yang lebih efektif dan efisien dalam memudahkan aktivitas sehari-hari, seperti bekerja, seperti pekerjaan industri yang berjalan pada perusahaan yang memproduksi kerupuk jangek, dimana dalam kegiatan industri tersebut dilakukan tahap penjemuran jangek yang akan di goring untuk di kemas dan di jual.

Penjemur kerupuk jangek adalah sebuah tempat untuk menjemur kerupuk jangek, dimana letak penjemuran berada di luar pabrik dan di buat di ruang terbuka agar jangek terkena sinar matahari secara langsung. Indonesia adalah Negara tropis 
yang memiliki dua musim yaitu musim hujan dan musim panas. Pada saat musim hujan tiba, mayoritas karyawan pabrik kerupuk jangek kelelahan karna harus bekerja ekstra mengeluarkan dan memasukan kerupuk jangek yang sedang di jemur akibat hujan yang tiba-tiba dating, maupun saat panas akan tetapi turun hujan.

Dengan permasalahan diatas penulis mencoba menyesaikan sebuah masalah tersebut menggunakan sebuah mikrokontroler arduino uno untuk mengubah sistem penjemuran yang manual menjadi otomatis dimana pejemur kerupuk jangek akan mengeluarkan sebuah tempat yang berisi kerupuk yang akan keringkan ketika sensor LDR terkena sebuah paparan sinar matahari dan akan menarik penutup kedalam ketika sensor air hujan terkena tetesan air hujan dimana semua input tersebut di kontrol oleh mikrokontoler arduino uno menggunakan metode fuzzy dimana metode tersebut adalah solusi untuk memecahkan masalah ketidak pastian atau samar seperti halnya panas namun hujan. Adapun semua letak dari mekanik penjemur kerupuk jangek berada di luar atau atap pabrik, dan segala alat elektonika yang mendukung kinerja dari sistem penggerak jemur berada di dalam ruangan yang kedap terhadap air hujan, maupun cairan lainnya, terkecuali sebuah sensor yang tahan air dan memang diharuskan diletak diluar ruangan terbuka seperti halnya sensor LDR dan sensor air hujan sebagai input terhadap sistem kecerdasaan buatan Arduino uno

\subsection{Penerapan Metode Fuzzy Logic}

Penjemur kerupuk jangek otomatis ini akan dibangun menggunakan mikrokontroler arduino uno sebagai pengontrol sebuah sensor yang akan menghidupkan motor dc yang menarik penjemur masuk dan keluar, sensor itu menggunakan sebuah sensor $L D R$ dan sensor air dimana ketika sensor $L D R$ terkena paparan sinar matahari maka moter dc akan bekerja untuk mengeluarkan penjemur ke tempat panas dan ketika sensor hujan terkena air hujan maka motor dc akan bekerja untuk menarik penjemur diluar kedalam agar tidak terkena hujan. Selain itu posisi panas akan tetapi hujan inilah yang menjadi masalah, oleh sebab itu metode fuzzy yang akan menentukan kesamaran pada saat kondisi panas hujan tersebut dimana penjemur kerupuk jangek akan tetap di luar terkena hujan atau menarik ke dalam agar tidak terkena hujan.

Teori himpunan fuzzy adalah merupakan perluasan dari teori logika Boolean yang menyatakan tingkat angka 1 atau 0 atau pernyataan benar atau salah, sedangkan pada teori logika fuzzy terdapata nilai keangggotaan suatu item x dalam suatu himpunan $\mathrm{A}$, yang sering ditulis dengan $\mu \mathrm{A}[\mathrm{x}]$, memiliki 2 kemungkinan yaitu : satu (1), yang berarti bahwa suatu item menjadi anggota dalam suatu himpunan, atau nol (0), yang berarti bahwa suatu item tidak menjadi anggota dalam suatu himpunan.

Himpunan input dan output ini menjelaskan nama variabel dan nilai variabel yang dirancang dalam sistem keamanan tas koper baru dimana setiap variabel diambil dari setiap sensor dan kondisi yang akan digunakan di dalam perancangan sistem keamanan tas koper dimana data variabel yang dibuat dalam bentuk tabel seperti berikut :

1. Variabel Sensor LDR (Light Dependent Resistor)

Tabel 1. Himpunan Kondisi Sensor LDR (Light Dependent Resistor)

\begin{tabular}{ccc}
\hline NO & Nama Variabel & Nilai variable \\
\hline 1 & Sangat Gelap & $0-200 \Omega$ \\
2 & Gelap & $200-350 \Omega$ \\
3 & Terang & $350-500 \Omega$ \\
\hline
\end{tabular}

2. Variabel Sensor Air Hujan

Tabel 2. Himpunan Kondisi Sensor LDR (Light Dependent Resistor)

\begin{tabular}{ccc}
\hline NO & Nama Variabel & Nilai variable \\
\hline 1 & Kering & $0-4$ milidetik \\
2 & Basah & $2-6$ milidetik \\
3 & Sangat Basah & $4-10$ milidetik \\
\hline
\end{tabular}

3. Variabel Kondisi Penarik Jemuran

Tabel 3. Himpunan Kondisi Motor Dc

\begin{tabular}{|c|c|c|}
\hline NO & Nama variable & Nilai variable \\
\hline 1 & Maju & 0 \\
\hline 2 & Mundur & 1 \\
\hline
\end{tabular}

Himpunan diagram ini menjelaskan nama variabel dan nilai variabel yang dirancang dalam jemuran otomatis dimana setiap vaibel diambil dari setiap sensor dan kondisi yang akan digunakan di dalam perancangan pejemur kerupuk otomatis dimana data varibel yang dibuat dalam seperti berikut :.

1. Diagram Kondisi Sensor LDR (Light Dependent Resistor)

Diagram ini menjelaskan nilai cahaya pada sensor LDR, penjelasan dapat dilihat pada gambar di bawah ini : 


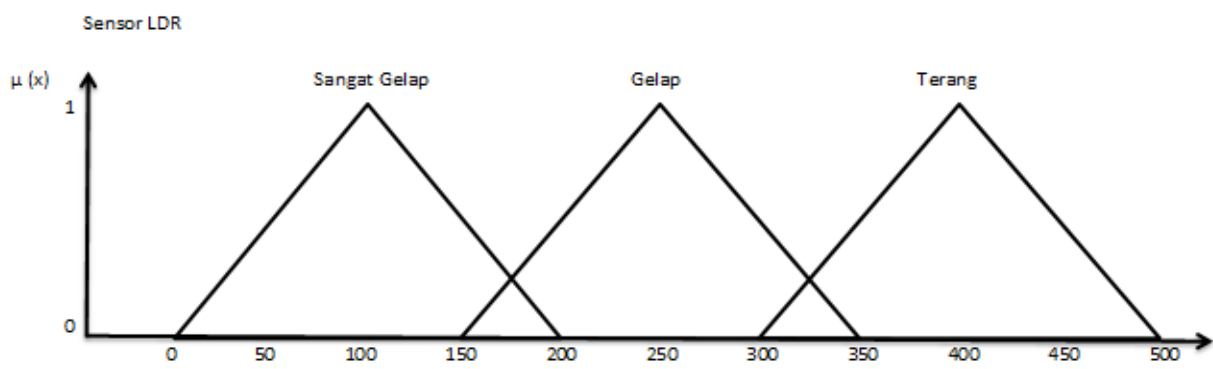

Gambar 1. Diagram Sensor LDR (Light Dependent Resistor)

2. Diagram Kondisi Sensor Air Hujan

Diagram ini menjelaskan banyaknya sensor terkena air hujan, penjelasan dapat dilihat pada gambar di bawah ini

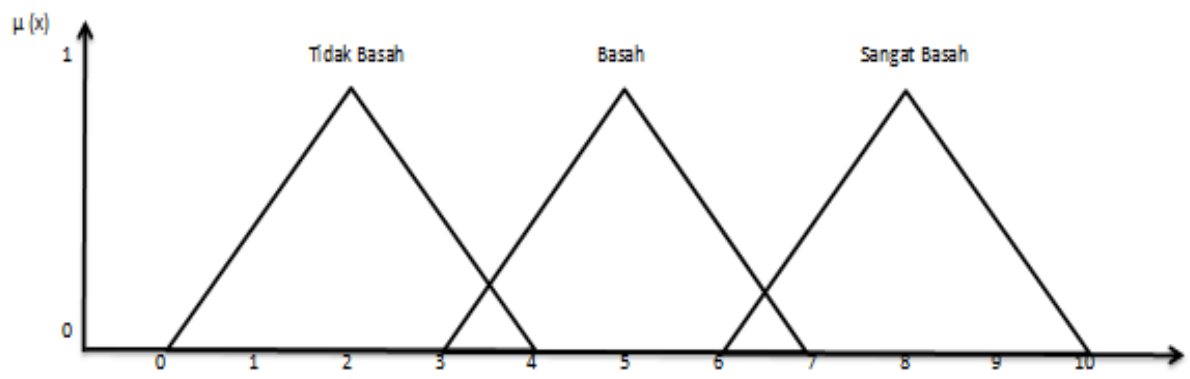

Gambar 2. Diagram Sensor Air Hujan

3. Diagram Motor Dc

Diagram ini menjelaskan kondisi motor de yang digunakan dalam jemuran otomatis, penjelasan dapat dilihat pada gambar di bawah ini :

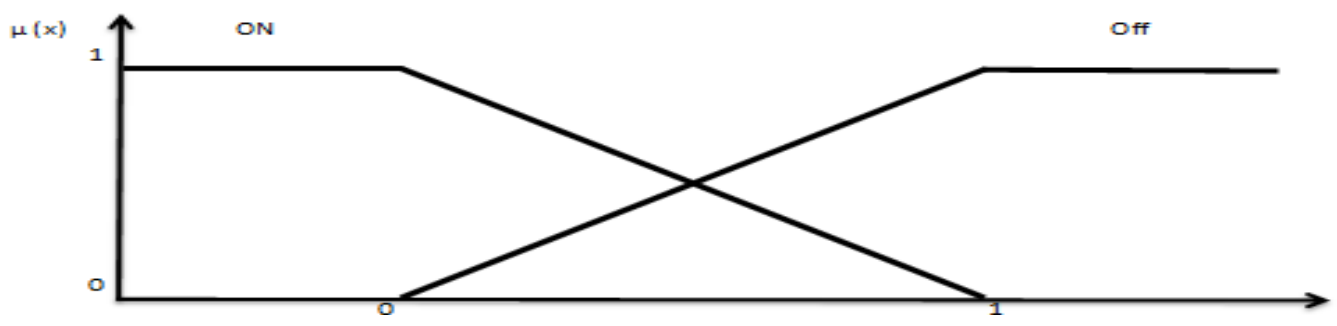

Gambar 3. Diagram Motor Dc

Berikut ini adalah rule dalam proses model mamdani yang terdapat 9 aturan Fuzzy, Yaitu: Berikut ini adalah rule dalam proses model mamdani yang terdapat 9 aturan Fuzzy. Yaitu:

1. If ( is Terang ) And (Sangat Basah) Then (Kedalam ).

2. If (is Terang ) And (Basah) Then (Kedalam ).

3. If ( is Terang ) And (Tidak Basah) Then ( Keluar ).

4. If ( is Gelap ) And (Sangat Basah) Then ( Kedalam ).

5. If ( is Gelap) And (Basah) And Then ( Kedalam ).

6. If ( is Gelap) And (Tidak Basah) Then (Keluar ).

7. If ( is Sangat Gelap ) And (Sangat Basah) Then ( Kedalam ).

8. If ( is Sangat Gelap ) And (Basah) Then (Kedalam ).

9. If ( is Sangat Gelap ) And (Tidak Basah) Then ( Keluar ).

Jika Sensor LDR Menangkap Sinar terang dan Sensor air hujan sangat basah maka kondisi penjemur ?

Dalam pengerjaan mamdani terlebih dahulu menetukan fuzzyfikasi seperti dalam penyelesaian berikut:

$\alpha$-predikat $=$ Terang $\cap$ Sangat Basah

$$
\begin{aligned}
\text { Terang [500] } & =(500-350) \\
& =150 / 500 \\
& =0.3 \\
\text { Sangat Basah [10] } & =(10-6) \\
& =4 / 10 \\
& =0.4
\end{aligned}
$$

Pembentukan diagram pada setiap sensor :

1. Diagram Variabel Sensor Cahaya 


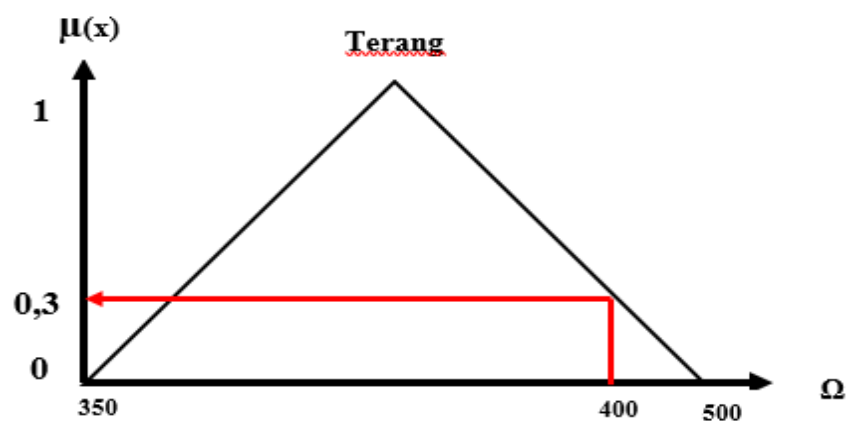

Gambar 4. Diagram Variabel Sensor LDR

2. Diagram Variabel Sensor Air Hujan

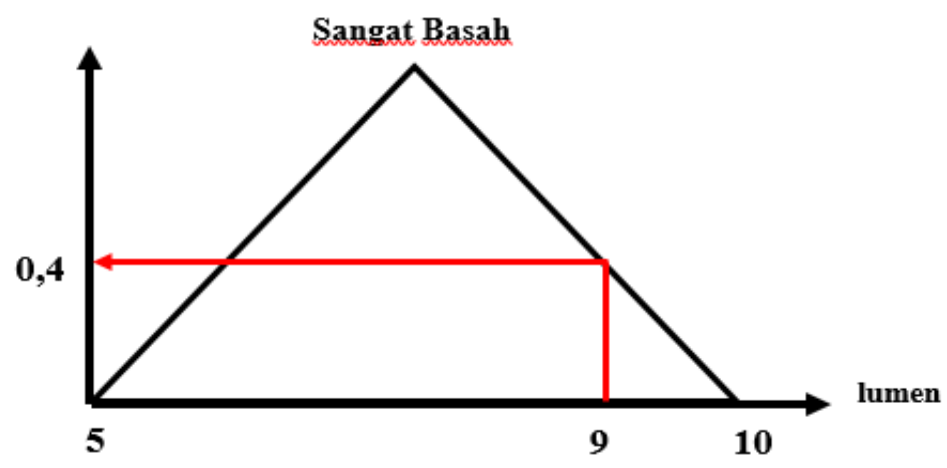

Gambar 5. Diagram Variabel Sensor Air Hujan

Hasil dari fuzzyfikasi akan dibentuk rule sebagai berikut :

$\alpha$-predikat $\quad=$ Terang $\cap$ Sangat Basah

$$
=\min (0.3 ; 0.4)
$$

$=\min 0.3$

$=\max 0.4$

Pada tahap selanjutnya adalah defuzzyfikasi,tahap ini menggunakan metode centroid :

(a1 - 0) $/ 100=0.4 \rightarrow 40$

$(\mathrm{a} 2-0) / 100=0.3 \rightarrow 30$

Pada tahap selanjutnya adalah defuzzyfikasi, tahap ini menggunakan metode centroid :

$Z^{*}=\frac{\int \mu(z) z d z}{\int \mu(z) d z}$

$Z^{*}=\underline{10-40+30}$

$6+40+30$

$Z^{*}=\frac{60}{76}$

$Z^{*}=0.7$

Setelah didapatkan hasil defuzzyfikasi, maka didapatkan nilai fuzzy 0.7 maka penarik akan menarik jemuran kedalam.

\subsection{Implementasi}

Pada tampilan program, sistem yang dibuat menggunakan sebuah alat mikrokontroler arduino uno dan software arduino ide 1.8.3, yang digunakan untuk merancang sistem pada penjemur kerupuk otomatis adalah sebuah software yan telah di-install pada operasi sistem seperti sistem windows maupun linux. Adapun tampilan dari software yang digunakan adalah sebagai berikut : 

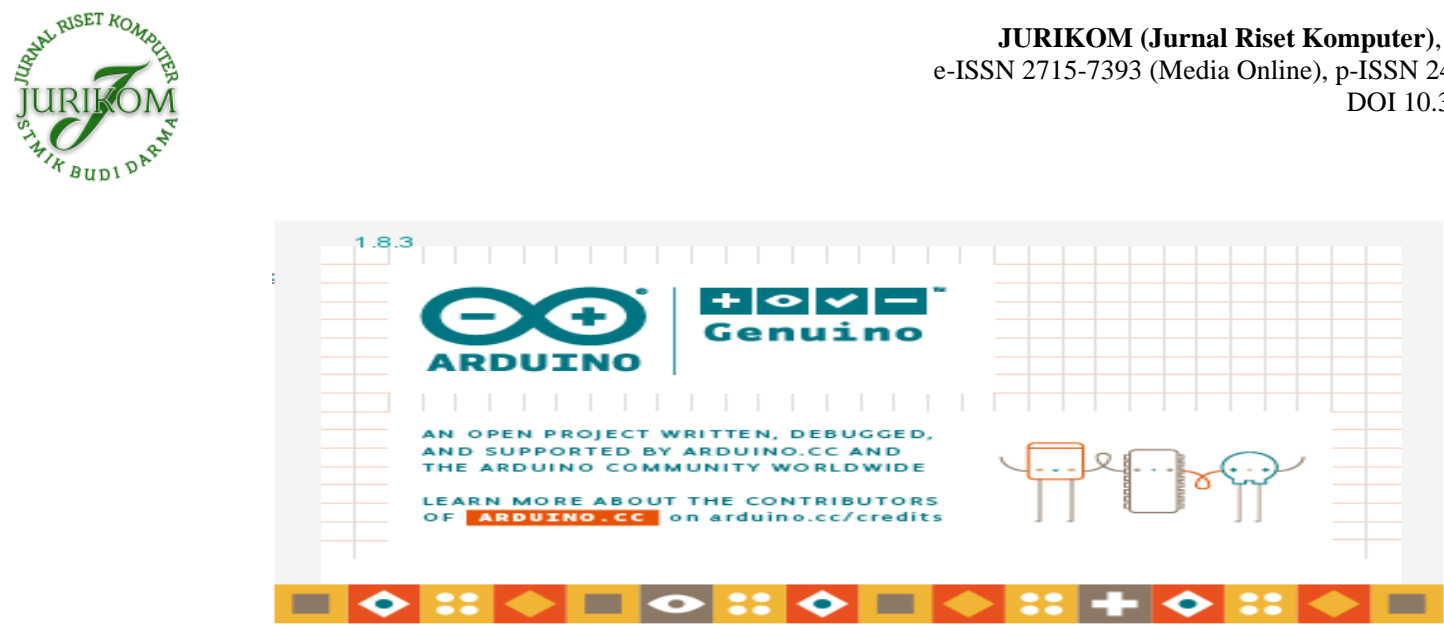

Gambar 6. Arduino IDE 1.8.3

Gambar di atas adalah sebuah tampilan startup ketika program dijalankan, menjalankan program tersebut bisa dengan menekan double klik pada mouse tehadap icon arduino pada desktop yang berbentuk angka 8 tertidur seperti gambar tampilan di atas. Setelah program terbuka maka akan tampil di menu utama program berupa sketch seperti berikut ini.

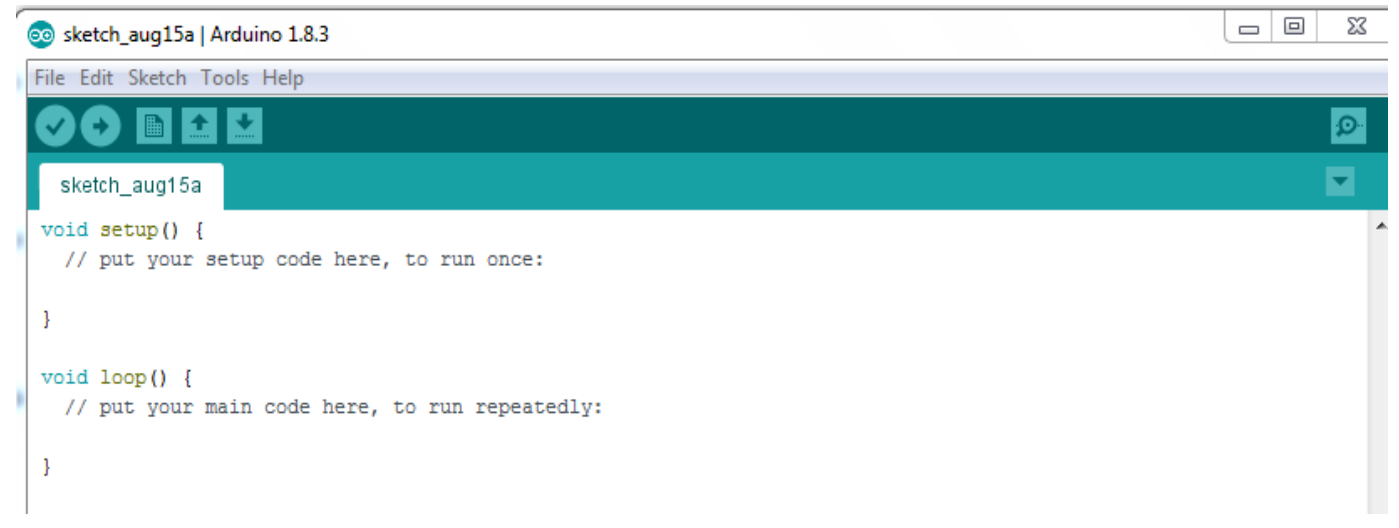

Gambar 7. Tampilan Sketch Arduino IDE 1.8.3

Adapun beberapa hasil pengujian dari pembuatan sistem yang diprogram menggunakan arduino ide 1.8.3 terhadap mikrokontroler arduino uno adalah sebagai berikut :

1. Sensor ldr (Light Defendant Resistor)

Pada sketch ldr digunakan sebagai input terhadap arduino uno yang disambungan dengan pin 3 pada mikrokontroler arduino uno adapun tampilan sketchnya adalah sebagai berikut :

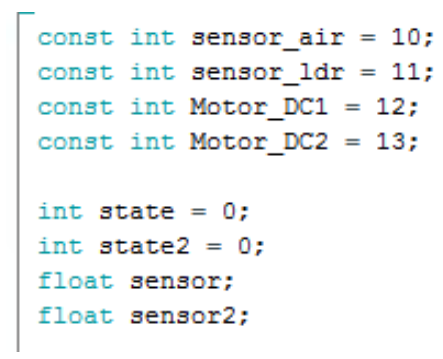

Gambar 8. Tampilan sketch sensor $l d r$

Gambar di atas adalah penempatan sensor $l d r$ pada pin 11 terhadap mikrokontroler arduino uno, serta menjadikannya sebuah input pada mikrokontroler arduino uno.

2. Sensor Air

Sensor air sama halnya dengan sensor $l d r$, sensor air merupakan sebuah input dari sistem penjemur kerupuk otomatis yang dihubungankan dengan mikrkontroler arduino uno, adapun tampilan sketch dari sensor air adalah sebagai berikut

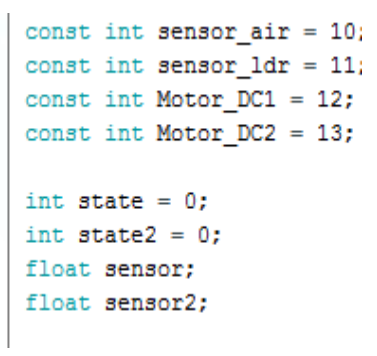

Gambar 9. Tampilan sketch sensor air 
Gambar di atas adalah tampilan sketch dari sensor air yang dimana sensor air dihubungkan pada pin 10 dan menjadi sebuah input terhadap mikrokontroler arduino uno.

3. Motor DC / Penarik Penjemur Kerupuk Otomatis

Motor DC atau penarik penjemur adalah sebuah output dari sistem yang dibuat, dimana motor dc ini akan hidup atau menarik penjemur kerupuk jangek apabila ada input dari sensor air dan sensor ldr. Adapun tampilan sketch Motor Dc atau penarik penjemur adalah sebagai berikut :

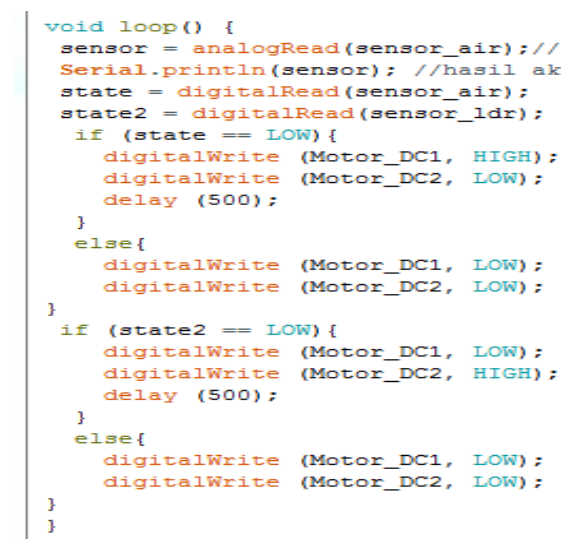

Gambar 10. Tampilan sketch Motor DC

Gambar di atas adalah tampilan sketch motor dc, dimana motor de di bagi menjadi dua yaitu motor dc1 dan motor dc2. Setiap motor dc mempunyai kerja berbeda dimana motor dc1 untuk menarik penjemur kerupuk kedalam dan motor dc2 untuk menarik penjemur kerupuk keluar. Motor dc ini akan bekerja apabila mikrokontroler arduino uno menerima input dari sensor air ataupun sensor ldr, dalam logika fuzzy logic yang diterapkan pada sistem penjemur kerupuk otomatis ini adalah bagaimana kondisi motor dc pada saat panas akan tetapi hujan, maka dibuat kondisi yang menempatkan prioritas pada kondisi input sensor air dan motordc 1. Apabila sensor menerima kondisi hujan meskipun panas maka motor dc1 akan menarik penjemur itu kedalam. Adapun tampilan dari keseluruhan sistem yang dirancang adalah sebagai berikut :
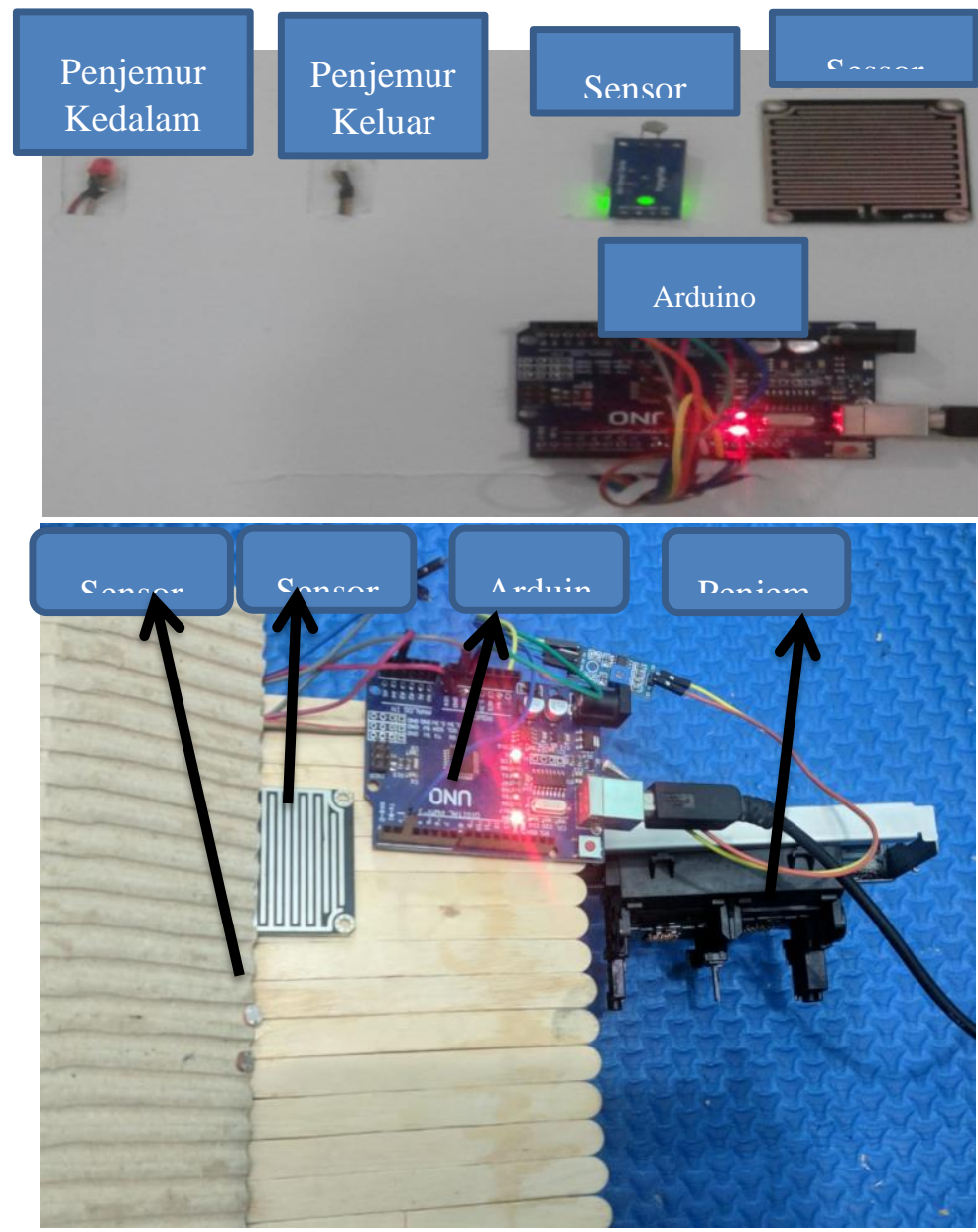

Gambar 11. Gambar Hadware Sistem Penjemur Kerupuk Jangek Otomatis 
Gambar di atas adalah sistem yang berbentuk sebuah hadware yang telah dilakukan pengujian dan menghasilkan output yang sesuai dengan program yang ditanamkan terhadap mikrokontroler arduino uno melalui contoh output terhadap lampu led.

\section{KESIMPULAN}

Berdasarkan hasil dari pengujian sistem penjemur kerupuk jangek otomatis menggunakan mikrokontroller arduino uno, dapat di ambil beberapa kesimpulan sebagai berikut :

1. Dengan menggunakan sistem ini dapat menyelasaikan dalam penjemur kerupuk jangek otomatis, dimana sistem ini akan memudahkan dalam penjemuran kerupuk jangek.

2. Proses ketidak pastian seperti halnya panas akan tetapi hujan inilah yang menjadi sebuah permasalahan, oleh sebab itu digunakan sebuah logika Fuzzy Logic Controller pada penerapan sistem yang dibuat. Dimana mikrokontroler Arduino uno tersebut mengontrol kapan penjemur kerupuk jangek akan memasukan dan mengeluarkan jangek yang akan di jemur.

3. Hasil yang di peroleh dari penjemur kerupuk otomatis ini hanya sebangai alat bantu bagi pengguna dalam penjemur kerupuk jangek.

\section{REFERENCES}

[1] Yulianti Paula Bria, "Pengembangan Aplikasi Fuzzy Logic Controller Untuk Pengereman Kereta Api Di Statiun Dan Simulasinya," Seminar Nasional Informatika 2012 (semnasIF2012), vol. C-143, Juni 2012.

[2] Pilipus Tarigan, Sinar Sinurat, Marzuki Sinambela, "Implementation of a Mamdani fuzzy logic controller for building automation using electronic control based on AT89S51," IEEE, 25 January 2016

[3] Ebta setiawan. (2018, January) Kamus Besar Bahasa Indonesia. [Online]. http://kbbi.web.id/otomatis

[4] Muhamad Muslihudin, Analisa dan Perancangan Sistem Informasi Menggunakan Terstruktural dan UML. Yogyakarta, Indonesia: CV. ANDI OFFSET, 2016.

[5] Dwi Ana Ratna Wati, Sistem Kendali Cerdas. Yogyakarta, Indonesia: Graha Ilmu, 2011.

[6] Heri Andrianto, ARDUINO BELAJAR CEPAT DAN PEMROGRAMAN. Bandung, Indonesia: Informatika Bandung, 2016.

[7] Solusi Rekaya Elekronika. (2017, June) Solusi Rekaya Elekronika. [Online]. http://www.vcc2gnd.com/sku/MDWTRDRS

[8] B. Sasikala S. Pooranchandra, Introduction to Electrical, Electronics and Communication Engineering. New Delh, India: Laxmi Publications (P) LTD, 2005.

[9] M.kom Drs. Lamhot Sitorus, Algoritma dan Pemrograman. Yogyakarta, Indonesia: CV. ANDI OFFSET, 2015. 